\title{
The History of Enterovirus A71 Outbreaks and Molecular Epidemiology in the Asia-Pacific Region
}

\author{
Jiratchaya Puenpa ${ }^{1}$, Nasamon Wanlapakorn ${ }^{1,2}$, Sompong Vongpunsawad ${ }^{1}$ and Yong Poovorawan ${ }^{1 *}$
}

\begin{abstract}
Enterovirus A71 (EV-A71) is one of the common causative pathogens for hand foot and mouth disease (HFMD) affecting young children. HFMD outbreak can result in a substantial pediatric hospitalization and burden the healthcare services, especially in less-developed countries. Since the initial epidemic of predominantly EV-A71 in California in 1969, the high prevalence of HFMD in the Asia-pacific region and elsewhere around the world represents a significant morbidity in this age group. With the advent of rapid and accurate diagnostic tools, there has been a dramatic increase in the number of laboratory-confirmed EV-A71 infection over the past two decades. The population, cultural, and socioeconomic diversity among countries in the Asia-Pacific region all influence the transmission and morbidity associated with HFMD. This review summarizes the current state of epidemiology of EV-A71 in Asia-Pacific countries based on the most recent epidemiological data and available information on the prevalence and disease burden. This knowledge is important in guiding the prevention, control and future research on vaccine development of this highly contagious disease of significant socioeconomic implications in public health.
\end{abstract}

Keywords: Enterovirus A71, Molecular epidemiology, Asia-Pacific region

\section{Introduction}

Infection by an enterovirus such as enterovirus A71 (EV-A71) can be asymptomatic or manifest as a selflimiting influenza-like illness. However, EV-A71 is one of the most important neurotropic viruses known. It is highly transmissible and infection results in hundreds of thousands of hospitalizations of children annually throughout the world, many of whom experienced severe or fatal neurologic consequences. EV-A71 has been recognized as the most common pathogen of the hand, foot, and mouth disease (HFMD), which is highly contagious and frequently affects young children below 5 years of age. EV-A71 can also occasionally cause serious neuropathology and cardiopulmonary complications, including aseptic meningitis, acute flaccid paralysis, brainstem encephalitis, and fatal myocarditis and pulmonary edema [1,2].

\footnotetext{
* Correspondence: Yong.P@chula.ac.th

${ }^{1}$ Center of Excellence in Clinical Virology, Department of Pediatrics, Faculty of Medicine, Chulalongkorn University, Bangkok, Thailand

Full list of author information is available at the end of the article
}

EV-A71 is a member of the genus Enterovirus within the family Picornaviridae. EV-A71 belongs to the species A enterovirus, which includes 25 other serotypes [3]. Although other members of the genus can infect multiple animals, EV-A71 only infects humans. The virus has a positive-sense, single-stranded RNA genome encapsidated in a non-enveloped capsid virion. The viral genome is approximately 7500 bases in length and is flanked by $5^{\prime}$ and $3^{\prime}$ untranslated regions (UTR) and a polyadenylated tail of variable length [4]. The single open reading frame (ORF) encodes a large polyprotein, which is proteolytically cleaved by the viral protease into structural protein P1 (VP1-VP4), and nonstructural proteins P2 (2A-2C) and P3 (3A-3D).

EV-A71 is transmitted predominantly via oral-fecal route, but also through contact with virus-contaminated oral secretions, vesicular fluid, surfaces and fomites. It can also be transmitted through direct contact with patient's aerosolized respiratory droplets [5]. EV-A71 can infect a wide range of cell types with different replicative capacity. Virus entry into susceptible host cells involves surface attachment, receptor binding and particle uptake

(c) The Author(s). 2019 Open Access This article is distributed under the terms of the Creative Commons Attribution 4.0 International License (http://creativecommons.org/licenses/by/4.0/), which permits unrestricted use, distribution, and 
into host cell through an endocytic pathway. The specific host cellular receptor for EV-A71 remains unknown, but until recently, there has been at least five different types of human cellular receptors identified so far. The first characterized receptor is the human scavenger receptor class B member 2 (SCARB2), also known as the lysosomal integral membrane protein II or CD36b like-2 [6]. SCARB2 was also identified to be a receptor for coxsackievirus genotypes A (CV)-A7, A14 and A16 [7]. The second characterized receptor is the human Pselectin glycoprotein ligand-1 (PSGL-1), a membrane protein expressed on leukocytes. Several studies have shown, however, that only some strains of EV-A71 utilize this receptor for cell entry [8]. The third characterized receptor is the sialic-acid-linked glycan, which is express in abundance in the respiratory and gastrointestinal epithelium cells [9]. The fourth receptor is human annexin 2 protein, which was identified as cellular host factor that interacts with EV-A71 during viral entry into human rhabdomyosarcoma (RD) cells [10]. The fifth attachment receptor is heparan sulfate glycosaminoglycan, which is widely expressed in all cell types [11]. Heparan sulfate was also observed to facilitate infection of RD cells by CV-A16, thereby serving as its receptor [12]. However a recent study identified KREMEN1 as an entry receptor for CV-A10 and other coxsackievirus A [13].

\section{A brief history and diagnosis of EV-A71}

Historically, EV-A71 was first isolated from the feces of a female encephalitis patient in 1969 in California [14]. A retrospective analysis by a group in The Netherlands suggests that it could have emerged there as early as 1963 [15], consistent with records of probable epidemic of EV-A71 in the late nineteenth century in the United States, Europe, Australia, and Asia [16]. Between 1972 and 1990, EV-A71 outbreaks were reported in New York (1972 and 1977) [17, 18], Sweden (1973) [19], Bulgaria (1975) [20], Hungary (1978) [21], The Netherlands (1986) [22], and Brazil (1988-1990) [23]. More recently, EV-A71 and other enterovirus A infections are recognized as a major public health concern, especially after yearly HFMD outbreaks in several Asia-Pacific countries. Clinical manifestation and severity of EV-A71 and other enterovirus infections are very similar, but their genetic background and pathogenic potential are notably different. As such, early and effective diagnostic techniques are required to differentiate these enteroviruses necessary for appropriate clinical management. Virus isolation has been the traditional diagnostic method to detect EVA71, which involves taking clinical samples from patients and culturing in a variety of cell lines of human (RD, HEK293, HEp-2, HeLa cells) or other primate origin (Vero and COS-7 cells) [24]. However, this method has gradually been replaced by more sensitive and rapid molecular diagnostics. Work pioneered by Oberste et al. $[25,26]$ utilizes reverse-transcription polymerase chain reaction (RT-PCR) assay to examine the VP1 region, which combined with nucleotide sequencing could reveal the viral serotypes. Nowadays, most diagnostic laboratories follow three basic techniques to definitively identify EV-A71, primarily isolation using tissue cultures, conventional immunological methods (indirect immunofluorescence and/or neutralization assay) [27], and nucleotide sequences from gene amplification using conventional and/or real-time RT-PCR [28]. The evolving methodologies used to diagnose and identify EV-A71 over the past decades have therefore confound the comparison of regional and temporal prevalence of EV-A71. In addition, variation in the detection methods used in different countries and settings may also influence the effectiveness of disease surveillance and ultimately mortality and morbidity rate reported in the literatures.

\section{EV-A71 circulation in the Asia-Pacific countries}

EV-A71 became endemic in the Asian-Pacific region by the 1990's and typically caused major outbreaks every 3-4 years. Countries with reported outbreaks include Malaysia [29], Taiwan [30, 31] and Singapore [32]. The overall mortality rate among patients diagnosed with EV-A71-associated HFMD in the Asian-Pacific countries has ranged from $<0.5$ to $19 \%$ [33-36]. Since 1997, an unprecedented increase in the number of EV-A71 infection has primarily been attributed to the circulation of two genotypes, B and C. Here, we compile reports of EV-A71 outbreaks in different countries of the Pacific region during the last two decades.

\section{Australia}

In 1973, an outbreak was reported in Melbourne, Australia, and again in Victoria in 1986, with 114 confirmed cases of EV-A71 (Fig. 1) [37, 38]. In 1999, Australia experienced outbreak in over an 8 month period with 6000 reported cases, of which 14 were clinically severe [39]. During the summer of 2000-2001, more EV-A71 cases were reported mainly in Sydney, which resulted in approximately 200 hospitalizations and 14 severe cases [40].

An epidemic of EV-A71 infection in Sydney occurred again during the first half of 2013. This outbreak first began in Sydney's northern beach community, then spread throughout the Sydney area [41]. An increasing number of severe neurological cases began in midNovember 2012, and HFMD cases surged in February 2013 and peaked in March. In this outbreak, there were nearly 120 severe cases reported, with EV-A71 being the predominant genotype (Fig. 1) [41, 42]. Pronounced clinical symptoms of suspected EV-A71 infection during this outbreak involved myoclonic jerks among patients with 


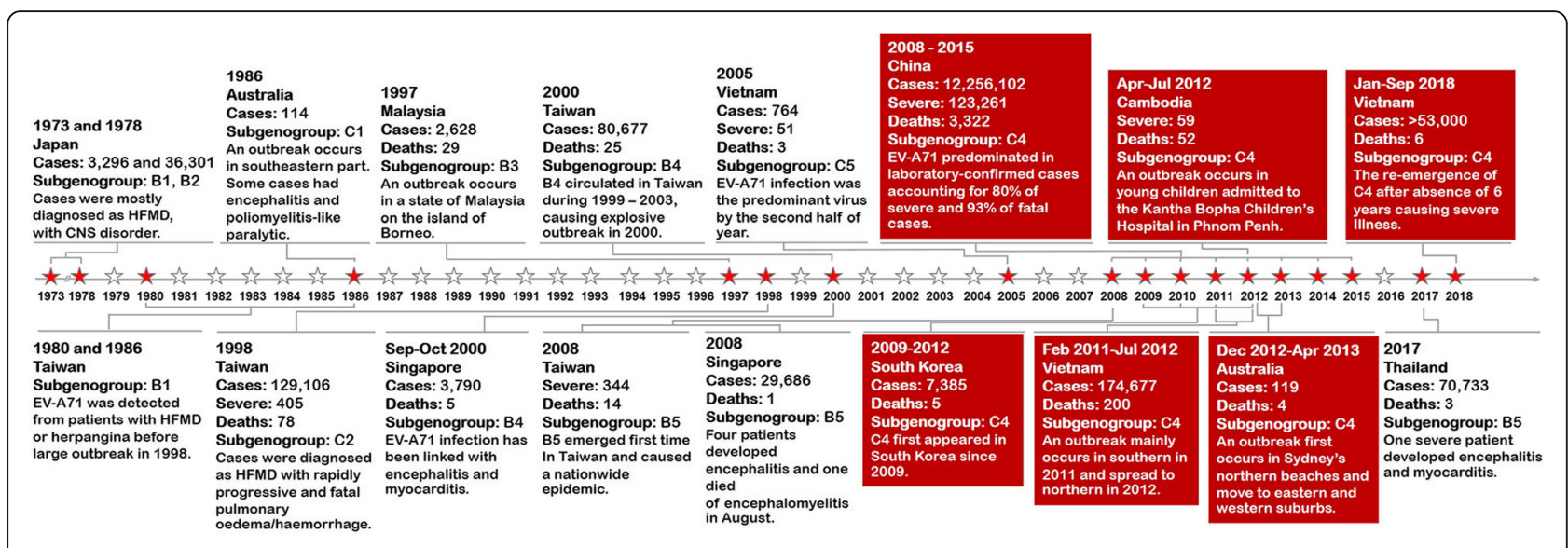

Fig. 1 Timeline of major EV-A71 outbreaks in Asia-Pacific countries

severe infection [41]. In all, there were four fatalities associated with EV-A71 neurological disease [43].

\section{Cambodia}

Although epidemiological reports have been scarce, an unprecedented EV-A71 epidemic was noted during the first half of 2012, including 56 deaths with severe encephalitis (Fig. 1). A high case-fatality rate of EV-A71 infection $(>60 \%)$ resulted from this outbreak [44].

\section{China}

Among the Asia-Pacific countries, China has the most number of EV-A71-associated HFMD outbreaks and the best epidemiological surveillance records in the past decade. It has been observed that the circulation of EV-A71 is particularly dynamic in this region. In 1987, an HFMD outbreak was firstly reported in Hubei province [16]. Although HFMD has been reported since the 1980's, disease etiology was not well-recognized until 2007 when $>80,000$ cases and 17 deaths were reported [45].

A comprehensive nationwide enhanced surveillance system for HFMD was established in China in May 2008 and fully implemented in July 2009 [46]. According to the Chinese Center for Disease Control and Prevention, there were approximately 13.7 million HFMD cases reported between 2008 and 2015, which include 123,261 severe cases and 3322 deaths (Fig. 1) [47, 48]. Between 2010 and 2012, the annual HFMD incidence in China during this period was at an all-time high. The prevalence ranged between 1221.3 and 1616.4 cases per million, with the most severe and fatal cases occurring in 2010 [46]. Although CV-A16 and other enteroviruses were also co-circulating, EV-A71 was observed in the majority of cases during the 8-year surveillance study (except for 2013 and 2015) [46, 48].

\section{Japan}

EV-A71 associated with the central nervous system disorders was described in Japan in 1973 and 1978 (Fig. 1)
$[49,50]$. National surveillance of HFMD has since been carried out by Japan's National Institute of Infectious Diseases in approximately 3000 pediatric medical sentinel sites by July 1981 [51]. HFMD in Japan has an epidemiological pattern with outbreaks averaging every 3 years, several of which occurred in last decade. During the summer of 2011, Japan had the largest epidemic of HFMD on record. A total of 347,362 cases were reported, with most cases occurring in children younger than 3 years of age [52]. CV-A6 infection was responsible in the majority of cases, with co-circulation of CVA16 and EV-A71 [53, 54]. Nationwide epidemics ensued in 2013, 2015 and 2017 with 1515 cases, 1590 cases and 1900 cases, respectively [55]. The outbreak in Japan has particular relevance because of the active circulation of CV-A6 since 2011, while EV-A71 was less predominantly observed in the epidemics of 2010 and 2012 [55]. Thereafter, EV-A71 was sporadically detected from October 2014 onward, but its increase activity began at the end of 2017 when it became the predominant serotype in 2018 with approximately 70,000 reported cases $[55,56]$.

\section{Malaysia}

EV-A71 infection with neurological complications and mortality was observed in Sarawak in April 1997, followed by reports in Peninsular Malaysia [57, 58]. According to the Sarawak State Department of Health, there were 2628 HFMD cases, including 29 deaths due to encephalitis and cardiac failure (Fig. 1) [59]. During this period, such encephalomyelitis associated with neurogenic pulmonary edema caused by EV-A71 infection in Kuala Lumpur were implicated in four fatal cases $[60,61]$. Concurrent with adenovirus, EV-A71 involvement resulted in myocardial failure and death during the HFMD outbreak in Sibu, Sarawak [62].

The Sarawak Health Department has a sentinel surveillance program for HFMD since March 1998 [63]. It showed that large epidemics occurred almost every 3 
years beginning in 2000 [63-67]. Epidemiological data suggest several common features of HFMD in Malaysia. First, the dominant EV-A71 genogroup B co-circulated with genogroup $\mathrm{C}$. The monthly cases of each epidemic cycle peaked early in the year from February to April. Additionally, there was a drastic drop in EV-A71 cases in the second and third year after the epidemic cycle (2001-2002 and 2004-2005) [63]. In 2006, there were 250 reported cases with central nervous system complication, including six deaths during EV-A71 epidemics in Sarawak [65]. According to the National Public Health Laboratory, EV-A71 was the most prevalent among the endemic cases between 2008 and 2009 [68].

\section{Singapore}

As a well-developed city-state with good public health and medical system, Singapore has long required reporting of many infectious diseases including HFMD. Reports of HFMD epidemics in Singapore have been reported in 1972 [69] and in 1981 [70]. Since then, occurrence of HFMD and aseptic meningitis associated with EV-A71 was reported in 1987 [16]. The highest recorded HFMD incidence occurred in 2000 when HFMD case numbers surged in early September, then peaked in October (3790 cases) [32]. There were a total of 76 laboratory-confirmed EV-A71 cases, of which 4 were fatal [32]. During 2001-2007, HFMD cases in Singapore were between 5187 and 20,003 cases annually [71]. Most enterovirus infections occurred in children < 4 years [71]. Monitoring of enterovirus reports showed that CVA16 (40\%) and EV-A71 (30\%) predominated at several children centers, kindergartens, and schools between 2001 and 2007 [71]. In 2008, Singapore experienced its largest HFMD outbreak involving approximately 30,000 HFMD cases (Fig. 1) [72]. Throughout 2008, CV-A6 and EV-A71 were the leading types, followed by CV-A10 [72].

\section{South Korea}

The Korea Centers for Disease Control and Prevention launched a national surveillance of enterovirus in 35 primary clinics, 105 secondary hospitals, and 40 tertiary hospitals nationwide since 1993. During 1999-2011, 4762 laboratory-confirmed enterovirus cases were recorded from the EV surveillance. Overall, around 15\% of all positive samples were EV-A71, followed by echovirus $30(13 \%)$ and CV-B5 (9\%) [73]. The first reported outbreak of EV-A71 in South Korea occurred in 2000, which involved 12 hospitalization cases [73, 74]. After an absence of 6 years, EV-A71 re-emerged and became endemic in South Korea with HFMD reported every year. An upsurge in severe HFMD disease in South Korea caused by EV-A71 occurred in 2009 beginning in the spring (Fig. 1) [73]. Official records showed that there were 2427 cases, of which 94 cases of laboratory- confirmed EV-A71 infection involved complications of the CNS and 2 deaths [2]. During this epidemic, the predominance of EV-A71 also co-incited with CV-A5 and CV-A6 circulation [2].

\section{Taiwan}

A nation of well-developed health and social infrastructure, the physician-based sentinel surveillance conducted by the Ministry of Health reported EV-A71-associated morbidity in 1980, 1981, and 1986 [30, 75, 76]. Taiwan experienced the largest epidemic in the year 1998, with an overall attack rate of $43 \%$ (Fig. 1) [30, 31, 77]. Viral transmission decreased during the summer season (July to September), and 2 epidemic waves were identified with peak incidences of 15,758 cases and 3177 cases during the week of June 7 and October 4, respectively [30, 31, 33]. In addition, unusual neurological complications were reported. In all, there were approximately 130,000 cases, of which 405 were severe and 78 were fatal $[1,30,31]$.

EV-A71 reemerged in Taiwan in 2000, 2001, 2005, 2008 and 2012. More than 600 severe cases and 51 deaths were reported to the Taiwan Center for Disease Control in both 2000 and 2001 consecutive years [78]. A total of 142 cases (16 fatal) were recorded in 2005 for the entire country, and EV-A71 infection was most common in children $\leq 4$ years of age $[79,80]$. There were 373 severe confirmed cases in 2008, of which 14 were fatal (Fig. 1) [81]. Infections peaked in June with 39 confirmed cases, similar to previous EV-A71 infection in 1998 in Taiwan [81]. The marked increase in EV-A71 infection paralleled reports from the National Cheng Kung University Medical Center in southern Taiwan that same year, which documented 367 cases. This figure was much higher than the EV-A71 case number in 2007 (1 case) and 2006 (no case) [82]. Other studies also confirmed that EV-A71 was also the most prevalent genotype found in northern Taiwan among the HFMD cases in 2008 and that some affected children experienced neurological complications [83-85]. For example, two children diagnosed with HFMD presented with brainstem encephalitis and cardiopulmonary failure [83, 84]. In addition, three HFMD patients had encephalomyelitis [85]. In 2012, HFMD outbreak again reemerged in Taiwan [86, 87]. EV-A71 in Taiwan appears seasonal and often peaks in the summer [88-90].

\section{Thailand}

Since 2001, the Bureau of Epidemiology at the Thai Ministry of Public Health has mandated hospital-based HFMD surveillance. During 2001-2018, the ministry reported a total of 502,329 HFMD cases (ranging between 769 and 79,910 cases annually) with the highest prevalence in 2016 [91]. Reports of HFMD incidence in Thailand from 2001 to 2011 were historically low [91] 
and ranged between 1.2 and 28.4 cases per 100,000 population. While the number of deaths from HFMD outbreaks declined from 7 in 2006 to 2 in 2012, the number of outbreak-related cases increased from 3961 in 2006 to 45,464 in 2012 [91]. This increase was mainly due to the first large-scale HFMD outbreak in 2012, which affected primarily infants and children (Fig. 2) [92]. Most cases were associated with CV-A6, but EVA71 infection constituted the third most prevalent type $[92,93]$. Subsequently, another nationwide HFMD outbreak in 2017 was not as severe as earlier ones [94], although EVA71 predominated in many provinces of Thailand in addition to CV-A6 and CV-A16 (Figs. 1and 2) [94].

Localized outbreaks of EV-A71 can occur regionally, as was seen in Northern provinces of Chiang Rai and Pha Yao in 2016 where the incidence rates were higher than in other regions [97]. Additionally, EV-A71 was the most prevalent genotype found in northern Thailand in which more than $55 \%$ of the cases occurred in children below 2 years of age [97]. In 2017, the Thai Ministry of Public Health had reported three mortality and an approximate count of 70,000 people who was infected with EVs [91]. The relatively rare fatal HFMD may be in part due to small proportion of enterovirus infection associated with EV-A71.

Improved tracking and surveillance has provided valuable epidemiological data in monitoring HFMD in Thailand. It is known that the percentage of outbreaks with molecular genotyping increased from $47 \%$ in 2009 to $69 \%$ in 2012 [92, 95]. Analysis of the clinical manifestation revealed that infections by coxsackieviruses and other enteroviruses differed in clinical signs and symptoms than infections caused by EV-A71 [97]. The rate of EV-A71 infection varied substantially throughout the year in Thailand and is historically highest during the rainy season [93, 96, 97]. EV-A71 infection is also detected in the drier seasons but at a lower frequency $[94,96]$.

\section{Vietnam}

The first official report of EV-A71 occurred in 2003 [98]. In the second half of 2005, Vietnam experienced an HFMD outbreak caused by EV-A71 with $>700$ confirmed cases, of which 51 were clinically severe and three were fatal [98]. Vietnam suffered the worst EVA71 epidemic in its recent history with an outbreak beginning in the early of 2011 and at week 38 (September $18-24$ ) of that year. By the end of 2012, there were almost 200,000 hospitalizations with 200 deaths, with a less than $0.5 \%$ case fatality rate (Fig. 1) [99]. Between 2013 and 2015, EV-A71 and CV-A6 were the most prevalent species among the endemic cases, followed by CV-A16 and CV-A10 [100]. In 2018, there was an

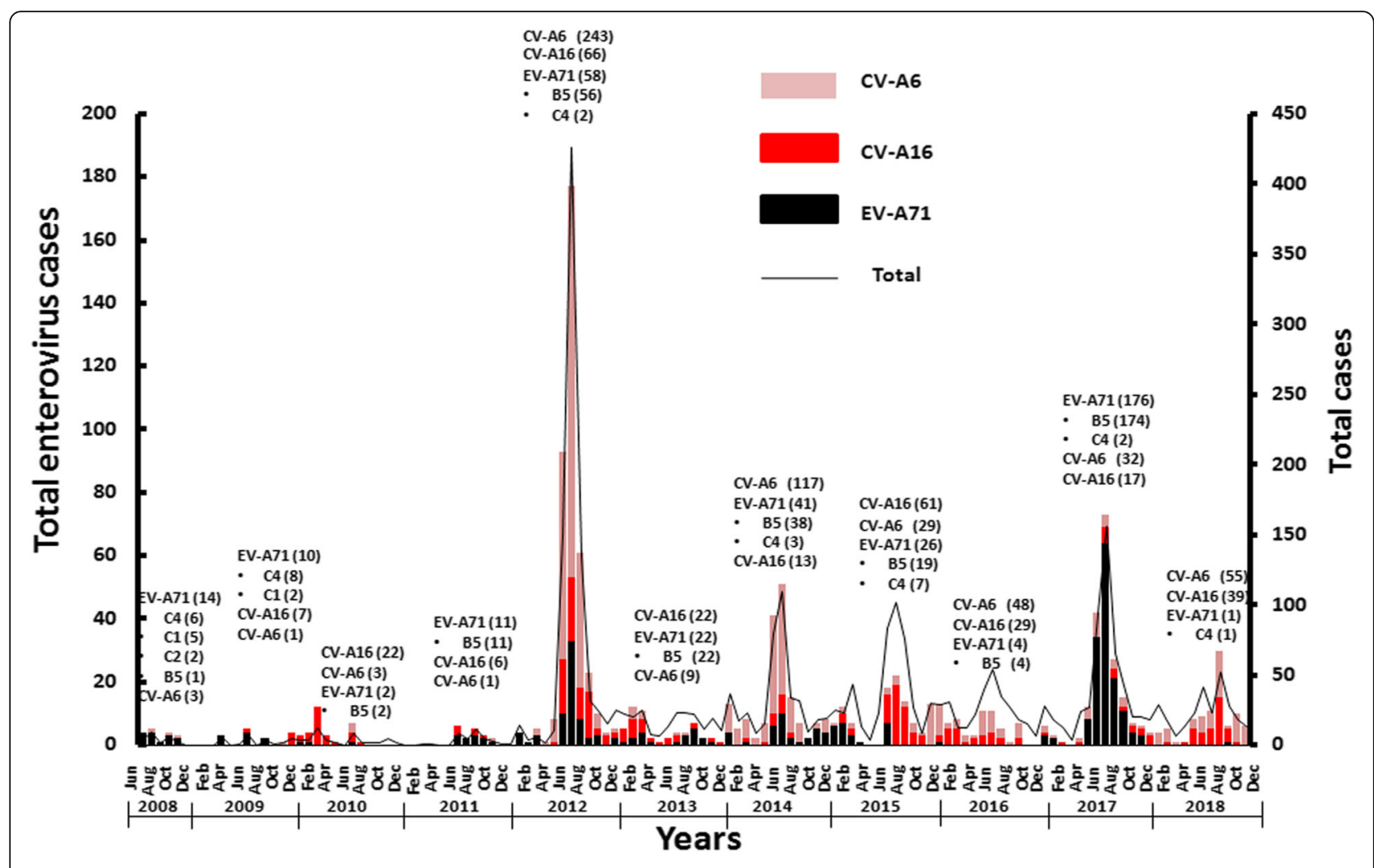

Fig. 2 Monthly number of suspected HFMD cases and distribution of predominant enterovirus genotypes in Thailand, during 2008-2018 [92-96]. 
increase in the number of cases, of which $>53,000$ hospitalizations and 6 deaths were reported. EV-A71 was also the predominant virus in this outbreak (Fig. 1) [101].

\section{Molecular epidemiology of EV-A71 suggests constant viral evolution}

Based on phylogenetic analysis of VP1 gene, EV-A71 is currently classified into four genotypes designated A, B, $C$ and D [102, 103]. Genotypes $B$ and $C$ are individually sub-classified into B1-B5 and C1-C5. New genotypes (E, $\mathrm{F}$, and G) were recently proposed, most of which were detected in central Africa, Madagascar, and India, respectively [104-106]. Genotype A was last isolated from an encephalitis case 50 years ago [14], no representative virus had been detected until 2008 [107].

Monitoring reports demonstrated that subgenogroup B1 and B2 predominated in America and Europe in the 1970s [45]. During the 80s, B2 was introduced into the United States, the Netherlands, Australia, and Japan [45]. In the early 1990s, a shift was observed in which subgenogroup $\mathrm{C} 1$ replaced $\mathrm{B} 2$ as the predominant genotype [45]. In contrast, subgenogroup B3 appears to be extinct since representatives of genotype in Singapore has not been found since 1999. Between 2000 and 2010, C2 was the predominant subgenogroup observed in AFP surveillance in Philippines [108]. Subgenogroup C3 was only isolated in South Korea in 2000 with sporadic cases (Table 1) [109].

In the first major HFMD outbreak in the Asia-Pacific region reported in Malaysia in 1997, molecular characterization showed that it was related to subgenogroups B3, B4, C1, and C2 (Fig. 3). Specifically, the predominance of $\mathrm{B} 3$ was specifically associated with fatal cases [59]. Later on in 2000 and 2003, B4 and B5 were the predominant subgenogroups (Fig. 3) [45]. Infections caused by subgenogroup $\mathrm{C} 1$ cases have generally been sporadic in Malaysia between 1997 and 2005 (Table 1) [45]. Subgenogroup B5 was detected in Brunei (2006) [117] and Indonesia (2016) [118]. Moreover, subgenogroup D, G and C1 circulated in India as endemic viruses between 2001 and 2012 [106].

In 1998, subgenogroup C4 emerged for the first time in the western Pacific region and caused severe epidemic beginning in China in 2008 [36, 110, 111]. C4 subsequently expanded to the rest of the region and caused major epidemics in several countries. Some of these outbreaks were associated with severe neurological complications and fatality cases, such as in Australia (2013) [41], Cambodia (2012) [44], Laos (2011) [119], Mongolia (2007, 2010) [120, 121], South Korea (2009-2012) [112], Vietnam (2011-2012 and 2018) (Table 1 and Fig. 3) [99, 101].

In Australia, outbreaks associated with subgenogroup C1 were reported in Victoria in 1986 and subgenogroup
C2 in Western Australia in 1999 [39]. A subgenogroup B4 epidemic was also reported in Sydney in 2000-2001 [39]. A switch from subgenogroup B4 to C4 in early 2013 was associated with a severe outbreak in Sydney (Table 1 and Fig. 3) [41].

In Taiwan, the yearly changes in EV-A71 subgenogroup distribution reflect the typical dynamic of enterovirus strain co-circulations in a given region. For example, although subgenogroup B1 circulated in 1980 and 1986 [30, 75, 76], the increase in HFMD incidence in Taiwan in 1998 strongly associated with subgenogroup $\mathrm{C} 2$, eclipsing $\mathrm{B} 1$ as causative subgenogroup [30, 113]. In 2000 and 2001, the endemic dominant subgenogroup in Taiwan is B4 [76, 113], which changed to $\mathrm{C4}$ after 2004 [76]. The emergence of the novel subgenogroups B5 has resulted in a large-scale nationwide epidemics in 2008 and 2012 (Table 1 and Fig. 3) [82, 86, 87, 114].

In Thailand, the distribution of EV-A71 subgenogroups varied by year [115]. Since 2001, enteroviruses monitoring in Thailand indicated the circulation of subgenogroups B4, B5, C1, C2, C4, and C5 (Fig. 3) [95, 115, 116]. During 2001 to 2004, molecularly confirmed EV-A71 belonged to subgenogroup $\mathrm{C} 1$, with subgenogroup $\mathrm{B} 4$ detected only rarely. However, notably, compared with the other subgenogroups, B5 first appeared in Thailand in 2006 and became the predominant subgenogroup beginning in 2010 (Table 1 and Fig. 3) [96]. During the EV-A71 B5 outbreak in 2017, two patients with subgenogroup C4 were also detected in the northern part, indicating the co-circulation of B5 and C4 in Thailand [94]. Subsequent subgenotypic replacement events of EV-A71 in Thailand have been observed in a different context. For instance, the prevalence of subgenogroup C4b displaced C4a in 2008 [115]. These observations provide evidence for the role of natural selection pressure in the replacement of the latter subgenogroups [122]. The existence of recombination within genome regions of subgenogroup B5 and $\mathrm{C} 4$ in Thailand was also demonstrated through comparison the results of similarity plot and bootscan analyses [123, 124].

In Vietnam, the co-circulation of $\mathrm{C} 1, \mathrm{C} 4$, and $\mathrm{C} 5$ subgenogroups responsible for HFMD outbreak in 2005 suggested the predominance of $\mathrm{C} 5$ in most affected children [98]. The emergence of subgenogroup C4 was implicated in a large-scale nationwide epidemic between 2011 and 2012 [99]. Subsequent emergence of subgenogroup B5 in 2012 became the dominant subgenogroup in 2013 [100]. The nationwide outbreak in Vietnam, which began in 2018, occurred after the absence of subgenogroup C4 for 6 years (Table 1 and Fig. 3) [101].

\section{Concluding Perspectives}

An upsurge in HFMD outbreaks associated with EVA71 occurred during the last decade. The changing 


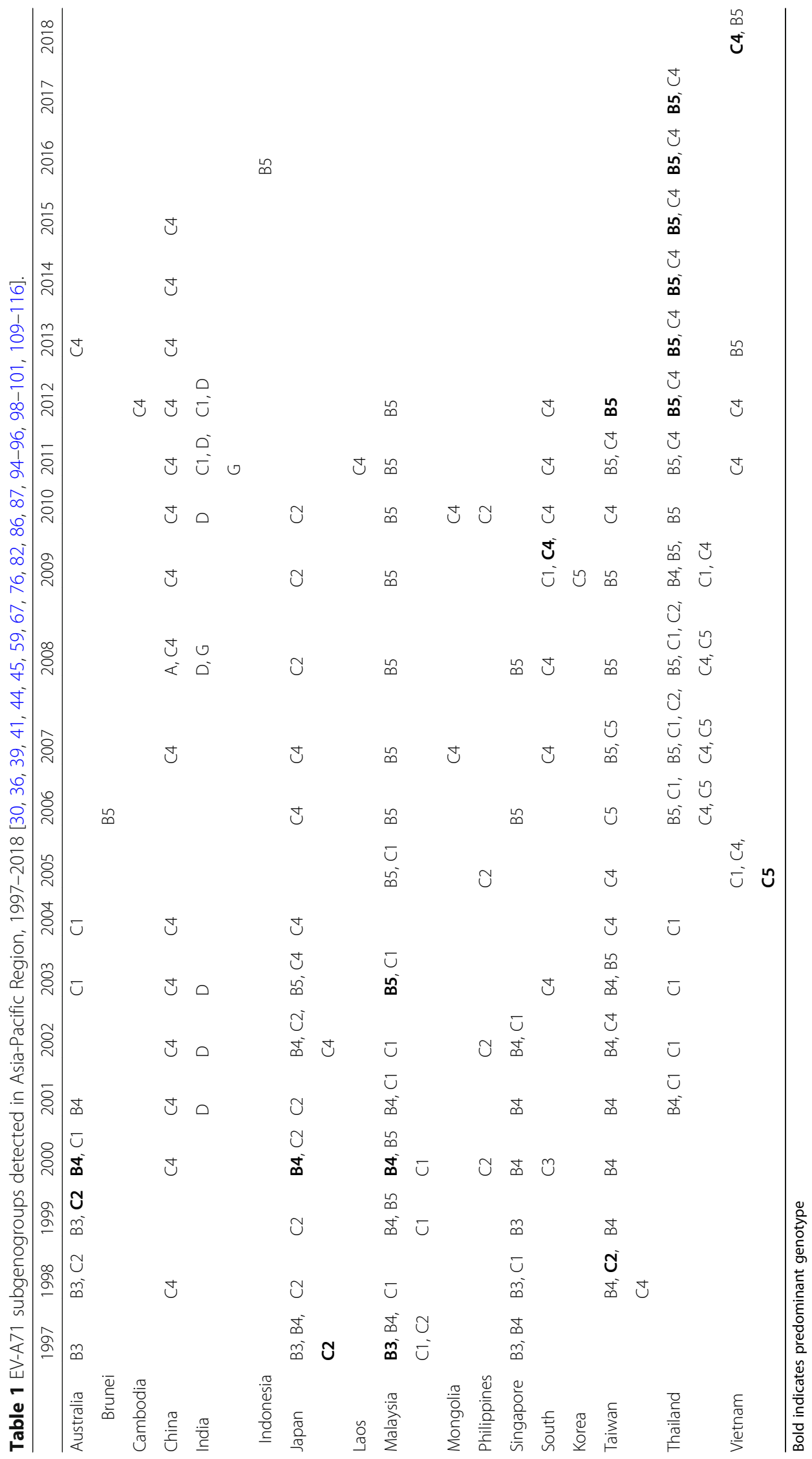




\section{(A) $1997-2007$}

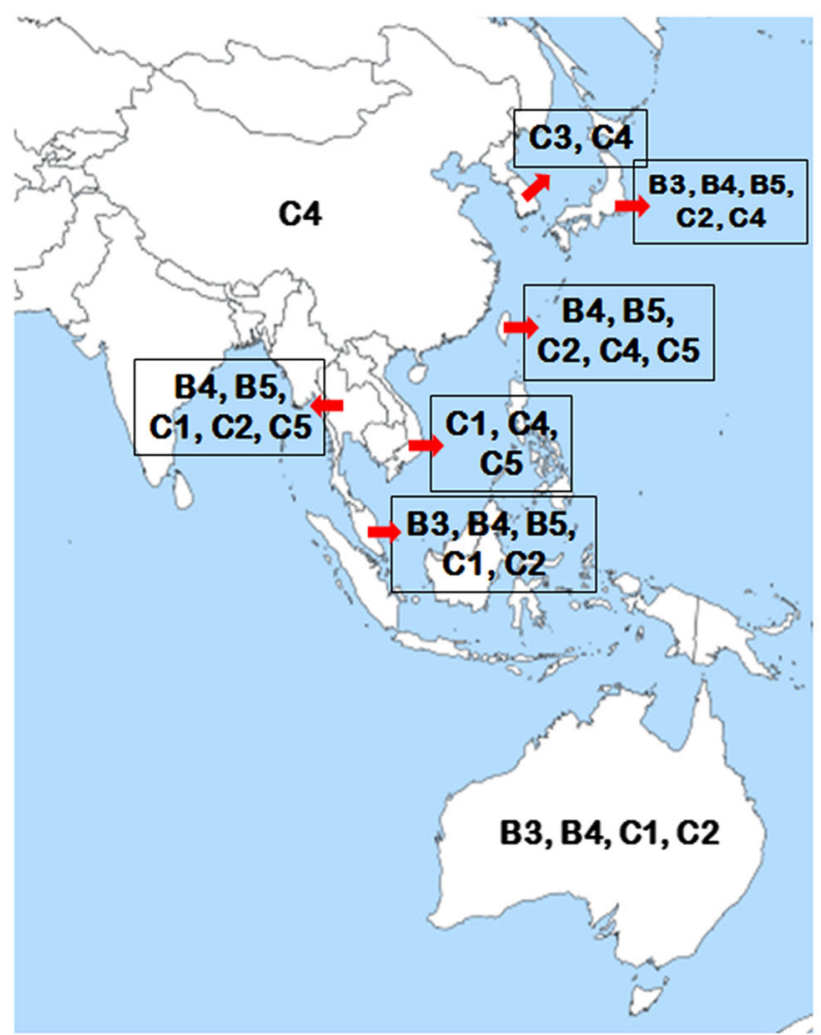

(B) 2008 - 2018

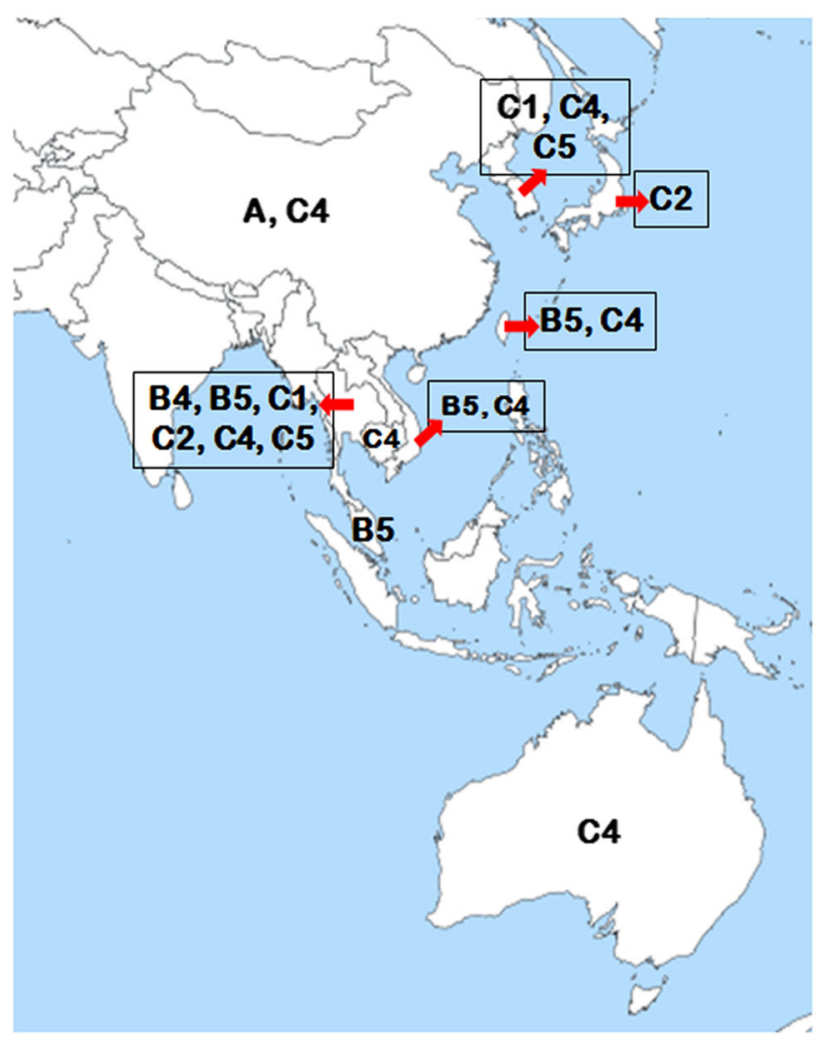

Fig. 3 Distribution of EV-A71 subgenogroups during (a) 1997-2007 and (b) 2008-2018

epidemiology of EV-A71 in Asia-Pacific countries has seen patterns of recurring outbreaks every 2-3 years with varying frequency and clinical severity. Outbreaks in Asia have shaped the development of fast and reliable multiplex real-time RT-PCR specific towards the most prevalent viruses associated with HFMD, namely EVA71, CV-A6, and CV-A16. As other EV types emerge, which could potentially replace the current viral circulation, new methods may be required to identify them with increasing accuracy. We have already seen that outbreaks in mainland China cause predominantly by the subgenotype $\mathrm{C} 4$ resulted in its inclusion in the vaccine. With new EV-A71 outbreaks, researchers gained additional genetic sequence information and clinicians identify additional range of symptoms, which assist in establishing patterns in disease progression and clinical outcome so valuable in the management of symptoms. Increased awareness of EV-A71 infection in the communities can potentially stem widespread transmission seen in past outbreaks, and fatalities associated with EV-A71 outbreaks appear to be on the decline, at least for now.

Currently, the availability of EV-A71 vaccine approved for use in some Asian countries may offer a partial solution in blunting disease transmission, but the lack of convincing evidence for the induction of crossprotection among the diversity of subgenogroups in circulation throughout the region and globally, including CV-A6 and CV-A16 associated with HFMD, remains to be addressed. In addition, it remains unclear what the optimal target age group and schedule for vaccination should be. Furthermore, the potential of the widespread use of the vaccine affecting the landscape of other EVA71 subgenotypes in circulation remains another concern. Ongoing development of multivalent vaccines demonstrating cross-protection against EV-A71/CV-A6/ CV-A16 could provide additional benefits towards the reduction of HFMD outbreaks. Additional strategies in preventing EV-related diseases burden, including the establishment of a regional HFMD disease network, transnational co-operation in vaccine research and evaluation, and standardized diagnostic methodologies with defined clinical characterization on a disease severity scale may assist in a more accurate capture of disease impact in this highly dynamic and culturally diverse region.

\section{Abbreviations}

CV-A: Coxsackievirus A; EV-A: Enterovirus A; EV-A71: Enterovirus A71; HFMD: Hand foot and mouth disease; ORF: Open reading frame; PSGL1: Human P-selectin glycoprotein ligand-1; RD: Rhabdomyosarcoma; RT- 
PCR: Reverse transcription polymerase chain reaction; SCARB2: Human scavenger receptor class B member 2; UTR: Untranslated regions

\section{Acknowledgments}

Not applicable.

\section{Authors' contributions}

JP drafted the manuscript and wrote the article. SV and YP revised and finished the final version of manuscript. All authors read and approved the final manuscript.

\section{Authors' information}

Dr. Puenpa is a postdoctoral fellow at the Center of Excellence in Clinical Virology, Department of Pediatrics, Faculty of Medicine, Chulalongkorn University in Bangkok. Her primary research interests are pediatric viral diseases and molecular epidemiology and evolution of human enterovirus.

\section{Funding}

This study was funded by the Research Chair Grant from the National Science and Technology Development Agency (P-15-5004), Ratchadaphiseksomphot Endowment Fund for Postdoctoral Fellowship to Jiratchaya Puenpa, the Center of Excellence in Clinical Virology at Chulalongkorn University (GCE59-00930-005), and King Chulalongkorn Memorial Hospital.

\section{Availability of data and materials}

Not applicable.

\section{Ethics approval and consent to participate}

Not applicable.

\section{Consent for publication}

Not applicable.

\section{Competing interests}

The authors declare that they have no competing interests.

\section{Author details}

${ }^{1}$ Center of Excellence in Clinical Virology, Department of Pediatrics, Faculty of Medicine, Chulalongkorn University, Bangkok, Thailand. ${ }^{2}$ Division of Academic Affairs, Faculty of Medicine, Chulalongkorn University, Bangkok, Thailand.

Received: 28 June 2019 Accepted: 1 October 2019 Published online: 18 October 2019

\section{References}

1. Wang SM, Liu CC, Tseng HW, Wang JR, Huang CC, Chen YJ, et al. Clinical spectrum of enterovirus 71 infection in children in southern Taiwan, with an emphasis on neurological complications. Clin Infect Dis. 1999;29(1):184-90.

2. Ryu WS, Kang B, Hong J, Hwang S, Kim A, Kim J, et al. Enterovirus 71 infection with central nervous system involvement, South Korea. Emerg Infect Dis. 2010;16(11):1764-6.

3. Stanway G, Brown F, Christian P, Hovi T, Hyypiä T, King AMQ, et al. Family Picornaviridae. In: Fauquet CM, Mayo MA, Maniloff J, Desselberger U, Ball LA, editors. Virus taxonomy. Eighth report of the international committee on taxonomy of viruses. London: Elsevier; 2005. p. 757-78.

4. Steil BP, Barton DJ. Cis-active RNA elements (CREs) and picornavirus RNA replication. Virus Res. 2009:139(2):240-52.

5. Pallansch MA, Roos R. Enteroviruses: polioviruses, coxsackieviruses, echoviruses, and newer enteroviruses. In: Fields Virology (Volumn 1). USA: Lippincott, Williams \& Wilkins; 2001. p. 840-84.

6. Yamayoshi S, Yamashita Y, Li J, Hanagata N, Minowa T, Takemura T, et al. Scavenger receptor B2 is a cellular receptor for enterovirus 71. Nat Med. 2009;15(7):798-801.

7. Yamayoshi S, lizuka S, Yamashita T, Minagawa H, Mizuta K, Okamoto M, et al. Human SCARB2-dependent infection by coxsackievirus A7, A14, and A16 and enterovirus 71. J Virol. 2012;86(10):5686-96.

8. Nishimura Y, Shimojima M, Tano Y, Miyamura T, Wakita T, Shimizu H. Human P-selectin glycoprotein ligand-1 is a functional receptor for enterovirus 71. Nat Med. 2009;15(7):794-7.
9. Yang $B$, Chuang $H$, Yang KD. Sialylated glycans as receptor and inhibitor of enterovirus 71 infection to DLD-1 intestinal cells. Virol J. 2009;6:141.

10. Yang SL, Chou YT, Wu CN, Ho MS. Annexin II binds to capsid protein VP1 of enterovirus 71 and enhances viral infectivity. J Virol. 2011;85(22):11809-20.

11. Tan CW, Poh CL, Sam IC, Chan YF. Enterovirus 71 uses cell surface heparin sulfate glycosaminoglycan as an attachment receptor. J Virol. 2013;87(1):611-20.

12. Zhang X, Shi J, Ye X, Ku Z, Zhang C, Liu Q, et al. Coxsackievirus A16 utilizes cell surface heparan sulfate glycosaminoglycans as its attachment receptor. Emerg Microbes Infect. 2017;6(7):e65.

13. Staring J, van den Hengel LG, Raaben M, Blomen VA, Carette JE, Brummelkamp TR. KREMEN1 Is a Host Entry Receptor for a Major Group of Enteroviruses. Cell Host Microbe. 2018;23:636-43.

14. Schmidt NJ, Lennette $\mathrm{EH}, \mathrm{Ho} H \mathrm{H}$. An apparently new enterovirus isolated from patients with disease of the central nervous system. J Infect Dis. 1974; 129(3):304-9.

15. van der Sanden S, Koopmans M, Uslu G, van der Avoort H, Dutch Working Group for Clinical Virology. Epidemiology of enterovirus 71 in the Netherlands, 1963 to 2008. J Clin Microbiol. 2009;47(9):2826-33.

16. McMinn PC. An overview of the evolution of enterovirus 71 and its clinical and public health significance. FEMS Microbiol Rev. 2002;26(1):91-107.

17. Melnick JL. Enterovirus type 71 infections: a varied clinical pattern sometimes mimicking paralytic poliomyelitis. Rev Infect Dis. 1984;6(Suppl 2):S387-90.

18. Deibel R, Gross LL, Collins DN. Isolation of a new enterovirus (38506). Proc Soc Exp Biol Med. 1975;148(1):203-7.

19. Blomberg J, Lycke E, Ahlfors K, Johnsson T, Wolontis S, von Zeipel G. New enterovirus type associated with epidemic of aseptic meningitis and/or hand, foot, and mouth disease. Lancet. 1974;2:112

20. Chumakov M, Voroshilova M, Shindarov L, Lavrova I, Gracheva L, Koroleva G, et al. Enterovirus 71 isolated from cases of epidemic poliomyelitis-like disease in Bulgaria. Arch Virol. 1979;60:32940.

21. Nagy G, Takatsy S, Kukan E, Mihaly I, Domok I. Virological diagnosis of enterovirus type 71 infections: experiences gained during an epidemic of acute CNS diseases in Hungary in 1978. Arch Virol. 1982;71:21727.

22. van der Sanden S, Koopmans M, Uslu G, van der Avoort H. Dutch Working Group for Clinical Virology. Epidemiology of enterovirus 71 in the Netherlands, 1963 to 2008. J Clin Microbiol. 2009:47:282633.

23. Takimoto S, Wadldman EA, Moreira RC, Kok F, Pinheiro Fde P, Saes SG, et al. Enterovirus 71 infection and acute neurological disease among children in Brazil (19981990). Trans R Soc Trop Med Hyg. 1998;92:258.

24. Victorio CB, Xu Y, Ng Q, Chow VT, Chua KB. Phenotypic and genotypic characteristics of novel mouse cell line (NIH/3T3)-adapted human enterovirus 71 strains (EV71:TLLm and EV71:TLLmv). PLoS One. 2014;9(3):e92719.

25. Oberste MS, Maher K, Kilpatrick DR, Flemister MR, Brown BA, Pallansch MA. Typing of human enteroviruses by partial sequencing of VP1. J Clin Microbiol. 1999:37(5):1288-93.

26. Oberste MS, Maher K, Kilpatrick DR, Pallansch MA. Molecular evolution of the human enteroviruses: correlation of serotype with VP1 sequence and application to picornavirus classification. J Virol. 1999;73(3):1941-8.

27. Rigonan AS, Mann L, Chonmaitree T. Use of monoclonal antibodies to identify serotypes of enterovirus isolates. J Clin Microbiol. 1998;36(7):1877-81.

28. World Health Organization. A guide to clinical management and public health response for hand, foot and mouth disease (HFMD), 2011. http://iris. wpro.who.int/handle/10665.1/5521. Accessed 12 May 2019.

29. Shekhar K, Lye MS, Norlijah O, Ong F, Looi LM, Khuzaiah R, et al. Deaths in children during an outbreak of hand, foot and mouth disease in Peninsular Malaysia-clinical and pathological characteristics. Med J Malaysia. 2005;60(3):297-304.

30. Ho M, Chen ER, Hsu KH, Twu SJ, Chen KT, Tsai SF, et al. An epidemic of enterovirus 71 infection in Taiwan. Taiwan Enterovirus Epidemic Working Group. N Engl J Med. 1999;341(13):929-35.

31. Chang LY, Lee CY, Kao CL, Fang TY, Lu CY, Lee PI, et al. Hand, foot and mouth disease complicated with central nervous system involvement in Taiwan in 1980-1981. J Formos Med Assoc. 2007;106(2):173-6.

32. Chan KP, Goh KT, Chong CY, Teo ES, Lau G, Ling AE. Epidemic hand, foot and mouth disease caused by human enterovirus 71, Singapore. Emerg Infect Dis. 2003;9(1):78-85.

33. Lin TY, Chang LY, Hsia SH, Huang YC, Chiu CH, Hsueh C, et al. The 1998 enterovirus 71 outbreak in Taiwan: pathogenesis and management. Clin Infect Dis. 2002:34(Suppl 2):S52-7.

34. Ooi MH, Wong SC, Podin Y, Akin W, del Sel S, Mohan A, et al. Human enterovirus 71 disease in Sarawak, Malaysia: a prospective clinical, virological, and molecular epidemiological study. Clin Infect Dis. 2007:44(5):646-56. 
35. Sun LM, Zheng HY, Zheng $H Z$, Guo X, He JF, Guan DW, et al. An enterovirus 71 epidemic in Guangdong Province of China, 2008: epidemiological, clinical, and virogenic manifestations. Jpn J Infect Dis. 2011;64(1):13-8.

36. Zhang $Y$, Zhu Z, Yang W, Ren J, Tan X, Wang Y, et al. An emerging recombinant human enterovirus 71 responsible for the 2008 outbreak of hand foot and mouth disease in Fuyang city of China. Virol J. 2010;7:94.

37. Kennett ML, Birch CJ, Lewis FA, Yung AP, Locarnini SA, Gust ID. Enterovirus type 71 infection in Melbourne. Bull World Health Organ. 1974;51(6):609-15.

38. Gilbert GL, Dickson KE, Waters MJ, Kennett ML, Land SA, Sneddon M. Outbreak of enterovirus 71 infection in Victoria, Australia, with a high incidence of neurologic involvement. Pediatr Infect Dis J. 1988;7(7):484-8.

39. Sanders SA, Herrero LJ, McPhie K, Chow SS, Craig ME, Dwyer DE, et al. Molecular epidemiology of enterovirus 71 over two decades in an Australian urban community. Arch Virol. 2006;151(5):1003-13.

40. Nolan MA, Craig ME, Lahra MM, Rawlinson WD, Prager PC, Williams GD, et al. Survival after pulmonary edema due to enterovirus 71 encephalitis. Neurology. 2003;60(10):1651-6.

41. Zander A, Britton PN, Navin T, Horsley E, Tobin S, McAnulty JM. An outbreak of enterovirus 71 in metropolitan Sydney: enhanced surveillance and lessons learnt. Med J Aust. 2014;201(11):663-6.

42. Horsley E, Just E, Torres C, Huhtinen E, Forssman B, Slade R. Enterovirus 71 outbreak in Northern Sydney, 2013: case series and initial response. J Paediatr Child Health. 2014;50(7):525-30.

43. Teoh HL, Mohammad SS, Britton PN, Kandula T, Lorentzos MS, Booy R, et al. Clinical Characteristics and Functional Motor Outcomes of Enterovirus 71 Neurological Disease in Children. JAMA Neurol. 2016;73(3):300-7.

44. Duong V, Mey C, Eloit M, Zhu H, Danet L, Huang Z, et al. Molecular epidemiology of human enterovirus 71 at the origin of an epidemic of fatal hand, foot and mouth disease cases in Cambodia. Emerg Microbes Infect. 2016;5(9):e104.

45. Lee MS, Tseng FC, Wang JR, Chi CY, Chong P, Su IJ. Challenges to licensure of enterovirus 71 vaccines. PLoS Negl Trop Dis. 2012;6(8):e1737.

46. Xing W, Liao Q, Viboud C, Zhang J, Sun J, Wu JT, et al. Hand, foot, and mouth disease in China, 2008-12: an epidemiological study. Lancet Infect Dis. 2014;14(4):308-18.

47. Huang J, Liao Q, Ooi MH, Cowling BJ, Chang Z, Wu P, et al. Epidemiology of Recurrent Hand, Foot and Mouth Disease, China, 2008-2015. Emerg Infect Dis. 2018;24(3):432-42.

48. Yang B, Liu F, Liao Q, Wu P, Chang Z, Huang J, et al. Epidemiology of hand, foot and mouth disease in China, 2008 to 2015 prior to the introduction of EV-A71 vaccine. Euro Surveill. 2017;22(50):1-10.

49. Ishimaru Y, Nakano S, Yamaoka K, Takami S. Outbreaks of hand, foot, and mouth disease by enterovirus 71. High incidence of complication disorders of central nervous system. Arch Dis Child. 1980;55(8):583-8.

50. Gobara F, Itagaki A, Ito Y, Saito K, Katsumoto T, Kimura G. Properties of virus isolated from an epidemic of hand-foot-and-mouth disease in 1973 in the city of Matsue. Microbiol Immunol. 1977;21:207-17.

51. Taniguchi K, Hashimoto S, Kawado M, Murakami Y, Izumida M, Ohta A, et al. Overview of infectious disease surveillance system in Japan, 1999-2005. J Epidemiol. 2007;17(Suppl):S3-13.

52. Infectious Agent Surveillance Report. Hand, foot and mouth disease in Japan, 2002-2011. https://www.niid.go.jp/niid/en/component/content/ article/865-iasr/1735-tpc385.html. Accessed 12 May 2019.

53. Infectious Agent Surveillance Report. Hand, foot, and mouth disease and herpangina, 2007 to September 2017 (week 38), Japan. 2017. https:/ www. niid.go.jp/niid/en/iasr-vol38-e/865-iasr/7617-452te.html. Accessed 12 May 2019.

54. Fujimoto T, lizuka S, Enomoto M, Abe K, Yamashita K, Hanaoka N, et al. Hand, foot, and mouth disease caused by coxsackievirus A6, Japan, 2011. Emerg Infect Dis. 2012;18(2):337-9.

55. Infectious Agent Surveillance Report. Hand, foot, and mouth disease and herpangina, 2009 to October 2018 (week 41), Japan. 2018. https://www.niid. go.jp/niid/ja/iasr/510- surveillance/iasr/surveillance/iasr/graphs/4892iasrgnatus.html. Accessed 12 May 2019.

56. World Health Organization (WHO) - Western Pacific Region: Hand, Foot and Mouth Disease Situation Update (Archives 2015, 2016, 2017 and 2018). https://www.who.int/westernpacific/emergencies/surveillance/archives/ hand-foot-and-mouth-disease. Accessed 13 May 2019.

57. World Health Organization. Outbreak of hand, foot and mouth disease in Sarawak. Cluster of deaths among infants and young children. Wkly Epidemiol Rec. 1997;72:211-2.

58. Hooi PS, Chua BH, Lee CS, Lam SK, Chua KB. Hand, foot and mouth disease: University Malaya Medical Centre experience. Med J Malaysia. 2002;57(1):88-91.
59. Chan LG, Parashar UD, Lye MS, Ong FG, Zaki SR, Alexander JP, et al. Deaths of children during an outbreak of hand, foot, and mouth disease in sarawak, malaysia: clinical and pathological characteristics of the disease. For the Outbreak Study Group. Clin Infect Dis. 2000;31(3):678-83.

60. Lum LC, Wong KT, Lam SK, Chua KB, Goh AY, Lim WL, Ong BB, Paul G, AbuBakar S, Lambert M. Fatal enterovirus 71 encephalomyelitis. J Pediatr. 1998;133(6):795-8.

61. Lum LC, Wong KT, Lam SK, Chua KB, Goh AY. Neurologic pulmonary oedema and enterovirus 71 encephalomyelitis. Lancet. 1998;352:1391.

62. Cardosa MJ, Krishnan S, Tio PH, Perera D, Wong SC. Isolation of subgenus B adenovirus during a fatal outbreak of enterovirus 71-associated hand, foot, and mouth disease in Sibu, Sarawak. Lancet. 1999;354(9183):987-91.

63. Podin Y, Gias EL, Ong F, Leong YW, Yee SF, Yusof MA, et al. Sentinel surveillance for human enterovirus 71 in Sarawak, Malaysia: lessons from the first 7 years. BMC Public Health. 2006;6:180.

64. Chua KB, Chua BH, Lee CS, Chem YK, Ismail N, Kiyu A, et al. Genetic diversity of enterovirus 71 isolated from cases of hand, foot and mouth disease in the 1997, 2000 and 2005 outbreaks, Peninsular Malaysia. Malays J Pathol. 2007;29(2):69-78.

65. Ooi MH, Wong SC, Mohan A, Podin Y, Perera D, Clear D, et al. Identification and validation of clinical predictors for the risk of neurological involvement in children with hand, foot, and mouth disease in Sarawak. BMC Infect Dis. 2009;9:3.

66. International Society for Infectious Diseases. Hand, foot \& mouth disease-Malaysia (SK) ProMEDmail 2012 March 22: 20120322.1077794. http://www.promedmail.org/post/20120322.1077794. Accessed 7 May 2019.

67. NikNadia N, Sam IC, Rampal S, WanNorAmalina W, NurAtifah G, Verasahib K, et al. Cyclical Patterns of Hand, Foot and Mouth Disease Caused by Enterovirus A71 in Malaysia. PLoS Negl Trop Dis. 2016;10(3):e0004562.

68. Chua KB, Kasri AR. Hand foot and mouth disease due to enterovirus 71 in Malaysia. Virol Sin. 2011;26(4):221-8.

69. Tay CH, Gaw CYN, Low T, Ong C, Chia KW, Yeo H, et al. Outbreak of hand, foot and mouth disease in Singapore. Singap Med J. 1974;15:174-83.

70. Goh KT, Doraisingham S, Tan JL, Lim GN, Chew SE. An outbreak of hand, foot, and mouth disease in Singapore. Bull World Health Organ. 1982;60(6): 965-9.

71. Ang LW, Koh BK, Chan KP, Chua LT, James L, Goh KT. Epidemiology and control of hand, foot and mouth disease in Singapore, 2001-2007. Ann Acad Med Singap. 2009;38(2):106-12.

72. Wu Y, Yeo A, Phoon MC, Tan EL, Poh CL, Quak SH, et al. The largest outbreak of hand; foot and mouth disease in Singapore in 2008: the role of enterovirus 71 and coxsackievirus A strains. Int J Infect Dis. 2010;14(12): e1076-81.

73. Hyeon JY, Hwang S, Kim H, Song J, Ahn J, Kang B, et al. Accuracy of diagnostic methods and surveillance sensitivity for human enterovirus, South Korea, 1999-2011. Emerg Infect Dis. 2013;19(8):1268-75.

74. Jee YM, Cheon DS, Kim K, Cho JH, Chung YS, Lee J, et al. Genetic analysis of the VP1 region of human enterovirus 71 strains isolated in Korea during 2000. Arch Virol. 2003;148(9):1735-46.

75. Liu CC, Tseng HW, Wang SM, Wang JR, Su IJ. An outbreak of enterovirus 71 infection in Taiwan, 1998: epidemiologic and clinical manifestations. J Clin Virol. 2000;17(1):23-30.

76. Lin KH, Hwang KP, Ke GM, Wang CF, Ke LY, Hsu YT, et al. Evolution of EV71 genogroup in Taiwan from 1998 to 2005: an emerging of subgenogroup C4 of EV71. J Med Virol. 2006;78(2):254-62.

77. Wu TN, Tsai SF, Li SF, Lee TF, Huang TM, Wang ML, et al. Sentinel surveillance for enterovirus 71, Taiwan, 1998. Emerg Infect Dis. 1999;5(3):458-60.

78. Lin TY, Twu SJ, Ho MS, Chang LY, Lee CY. Enterovirus 71 outbreaks, Taiwan: occurrence and recognition. Emerg Infect Dis. 2003;9(3):291-3.

79. Lan YC, Lin TH, Tsai JD, Yang YC, Peng CT, Shih MC, et al. Molecular epidemiology of the 2005 enterovirus 71 outbreak in central Taiwan. Scand J Infect Dis. 2011:43(5):354-9.

80. Chen SC, Chang HL, Yan TR, Cheng YT, Chen KT. An eight-year study of epidemiologic features of enterovirus 71 infection in Taiwan. Am J Trop Med Hyg. 2007;77(1):188-91.

81. Center for Disease Control, Taiwan. Enterovirus infection with severe complications in Taiwan - Trend in 2008. https://nidss.cdc.gov.tw/ en/SingleDisease.aspx $? \mathrm{dc}=1 \& \mathrm{dt}=4 \&$ disease $=0749 \&$ position $=1$. Accessed 28 Apr 2019.

82. Huang SW, Hsu YW, Smith DJ, Kiang D, Tsai HP, Lin KH, et al. Reemergence of enterovirus 71 in 2008 in taiwan: dynamics of genetic and antigenic evolution from 1998 to 2008. J Clin Microbiol. 2009;47(11):3653-62. 
83. Lee MH, Huang LM, Wong WW, Wu TZ, Chiu TF, Chang LY. Molecular diagnosis and clinical presentations of enteroviral infections in Taipei during the 2008 epidemic. J Microbiol Immunol Infect. 2011;44(3):178-83.

84. Chen SP, Huang YC, Li WC, Chiu CH, Huang CG, Tsao KC, et al. Comparison of clinical features between coxsackievirus A2 and enterovirus 71 during the enterovirus outbreak in Taiwan, 2008: a children's hospital experience. J Microbiol Immunol Infect. 2010;43(2):99-104.

85. Hsu CH, Lu CY, Shao PL, Lee PI, Kao CL, Chung MY, et al. Epidemiologic and clinical features of non-polio enteroviral infections in northern Taiwan in 2008. J Microbiol Immunol Infect. 2011;44(4):265-73.

86. Wu WH, Kuo TC, Lin YT, Huang SW, Liu HF, Wang J, et al. Molecular epidemiology of enterovirus 71 infection in the central region of Taiwan from 2002 to 2012. PLoS One. 2013;8(12):e83711.

87. Luo ST, Chiang PS, Chung WY, Chia MY, Tsao KC, Wang YH, et al. Reemergence of enterovirus 71 epidemic in northern Taiwan, 2012. PLoS One. 2015;10(3):e0116322.

88. Huang YP, Lin TL, Hsu LC, Chen YJ, Tseng YH, Hsu CC, et al. Genetic diversity and C2-like subgenogroup strains of enterovirus 71, Taiwan, 2008. Virol J. 2010;7:277.

89. Chen KT, Chang HL, Wang ST, Cheng YT, Yang JY. Epidemiologic features of hand-foot-mouth disease and herpangina caused by enterovirus 71 in Taiwan, 1998-2005. Pediatrics. 2007;120(2):e244-52.

90. Chang HL, Chio CP, Su HJ, Liao CM, Lin CY, Shau WY, et al. The association between enterovirus 71 infections and meteorological parameters in Taiwan. PLoS One. 2012;7(10):e46845.

91. Bureau of Epidemiology, Department of Disease Control MoPH, Thailand: Hand Foot and Mouth Disease: Situation update (article in Thai). http:// www.boe.moph.go.th/boedb/surdata/disease.php?dcontent=old\&ds=71. Accessed 18 March 2019.

92. Puenpa J, Chieochansin T, Linsuwanon P, Korkong S, Thongkomplew S, Vichaiwattana $P$, et al. Hand, foot, and mouth disease caused by coxsackievirus A6, Thailand, 2012. Emerg Infect Dis. 2013;19(4):641-3.

93. Puenpa J, Mauleekoonphairoj J, Linsuwanon P, Suwannakarn K, Chieochansin T, Korkong S, et al. Prevalence and characterization of enterovirus infections among pediatric patients with hand foot mouth disease, herpangina and influenza like illness in Thailand, 2012. PLoS One. 2014;9(6):e98888.

94. Puenpa J, Auphimai C, Korkong S, Vongpunsawad S, Poovorawan Y. Enterovirus A71 Infection, Thailand, 2017. Emerg Infect Dis. 2018;24(7):1386-7.

95. Puenpa J, Theamboonlers A, Korkong S, Linsuwanon P, Thongmee C, Chatproedprai $\mathrm{S}$, et al. Molecular characterization and complete genome analysis of human enterovirus 71 and coxsackievirus A16 from children with hand, foot and mouth disease in Thailand during 2008-2011. Arch Virol. 2011;156(11):2007-13.

96. Linsuwanon P, Puenpa J, Huang SW, Wang YF, Mauleekoonphairoj J, Wang $J R$, et al. Epidemiology and seroepidemiology of human enterovirus 71 among Thai populations. J Biomed Sci. 2014;21:16.

97. Upala P, Apidechkul T, Suttana W, Kullawong N, Tamornpark R, Inta C. Molecular epidemiology and clinical features of hand, foot and mouth disease in northern Thailand in 2016: a prospective cohort study. BMC Infect Dis. 2018;18(1):630

98. Van Tu P, Thao NTT, Perera D, Truong KH, Tien NTK, Thuong TC, et al. Epidemiologic and virologic investigation of hand, foot, and mouth disease, southern Vietnam, 2005. Emerg Infect Dis. 2007;13(11):1733-41.

99. Khanh TH, Sabanathan S, Thanh TT, le PK T, Thuong TC, Hang V, et al. Enterovirus 71-associated hand, foot, and mouth disease, Southern Vietnam, 2011. Emerg Infect Dis. 2012;18(12):2002-5.

100. Hoang MTV, Nguyen TA, Tran TT, Vu TTH, Le NTN, Nguyen THN, et al. Clinical and aetiological study of hand, foot and mouth disease in southern Vietnam, 2013-2015: Inpatients and outpatients. Int J Infect Dis. 2019;80:1-9.

101. Nhan LNT, Hong NTT, Nhu LNT, Nguyet LA, Ny NTH, Thanh TT, et al. Severe enterovirus A71 associated hand, foot and mouth disease, Vietnam, 2018: preliminary report of an impending outbreak. Euro Surveill. 2018;23(46):1-5.

102. Brown BA, Oberste MS, Alexander JP Jr, Kennett ML, Pallansch MA Molecular epidemiology and evolution of enterovirus 71 strains isolated from 1970 to 1998. J Virol. 1999;73(12):9969-75.

103. Rao CD, Yergolkar P, Shankarappa KS. Antigenic diversity of enteroviruses associated with nonpolio acute flaccid paralysis, India, 2007-2009. Emerg Infect Dis. 2012;18(11):1833-40.

104. Bessaud M, Pillet S, Ibrahim W, Joffret ML, Pozzetto B, Delpeyroux F, et al. Molecular characterization of human enteroviruses in the Central African
Republic: uncovering wide diversity and identification of a new human enterovirus A71 genogroup. J Clin Microbiol. 2012;50(5):1650-8.

105. Bessaud M, Razafindratsimandresy R, Nougairède A, Joffret ML, Deshpande $J M$, Dubot-Pérès A, et al. Molecular comparison and evolutionary analyses of VP1 nucleotide sequences of new African human enterovirus 71 isolates reveal a wide genetic diversity. PLoS One. 2014;9:e90624.

106. Saxena VK, Sane S, Nadkarni SS, Sharma DK, Deshpande JM. Genetic diversity of enterovirus A71, India. Emerg Infect Dis. 2015;21(1):123-6.

107. Yu H, Chen W, Chang H, Tang R, Zhao J, Gan L, et al. Genetic analysis of the VP1 region of enterovirus 71 reveals the emergence of genotype $A$ in central China in 2008. Virus Genes. 2010:41(1):1-4.

108. Apostol LN, Shimizu H, Suzuki A, Umami RN, Jiao MMA, Tandoc A 3rd, Saito M, Lupisan S, Oshitani H. Molecular characterization of enterovirus-A71 in children with acute flaccid paralysis in the Philippines. BMC Infect Dis. 2019;19(1):370.

109. Huang SW, Kiang D, Smith DJ, Wang JR. Evolution of re-emergent virus and its impact on enterovirus 71 epidemics. Exp Biol Med (Maywood). 2011;236(8):899-908.

110. Yang F, Ren L, Xiong Z, Li J, Xiao Y, Zhao R, et al. Enterovirus 71 outbreak in the People's Republic of China in 2008. J Clin Microbiol. 2009;47(7):2351-2.

111. Zhang Y, Tan XJ, Wang HY, Yan DM, Zhu SL, Wang DY, et al. An outbreak of hand, foot, and mouth disease associated with subgenotype C4 of human enterovirus 71 in Shandong, China. J Clin Virol. 2009:44(4):262-7.

112. Kim HJ, Hyeon JY, Hwang S, Lee YP, Lee SW, Yoo JS, et al. Epidemiology and virologic investigation of human enterovirus 71 infection in the Republic of Korea from 2007 to 2012: a nationwide cross-sectional study. BMC Infect Dis. 2016;16(1):425.

113. Wang JR, Tuan YC, Tsai HP, Yan JJ, Liu CC, Su IJ. Change of major genotype of enterovirus 71 in outbreaks of hand-foot-and-mouth disease in Taiwan between 1998 and 2000. J Clin Microbiol. 2002;40(1):10-5.

114. Lee MS, Lin TY, Chiang PS, Li WC, Luo ST, Tsao KC, et al. An investigation of epidemic enterovirus 71 infection in Taiwan, 2008: clinical, virologic, and serologic features. Pediatr Infect Dis J. 2010;29(11):1030-4.

115. Noisumdaeng P, Korkusol A, Prasertsopon J, Sangsiriwut K, Chokephaibulkit K, Mungaomklang A, et al. Longitudinal study on enterovirus A71 and coxsackievirus A16 genotype/subgenotype replacements in hand, foot and mouth disease patients in Thailand, 2000-2017. Int J Infect Dis. 2019;80:84-91.

116. Chatproedprai S, Theanboonlers A, Korkong S, Thongmee C, Wananukul S, Poovorawan Y. Clinical and molecular characterization of hand-foot-andmouth disease in Thailand, 2008-2009. Jpn J Infect Dis. 2010;63(4):229-33.

117. AbuBakar S, Sam IC, Yusof J, Lim MK, Misbah S, MatRahim N, Hooi PS. Enterovirus 71 outbreak. Brunei Emerg Infect Dis. 2009;15(1):79-82.

118. Wiyatno A, Hartoyo E, Jaya UA, Ma'roef CN, Myint KS, Gillis A, et al. Detection and genetic characterization of human enteroviurs $A 71$ from hand, foot and mouth disease cases in Banjarmasin, Indonesia. Southeast Asian J Trop Med Public Health. 2018:49(5):820-5.

119. Nguyen VH, Sibounheuang B, Phommasone K, Vongsouvath $M$, Newton PN, Piorkowski G, Baronti C, de Lamballerie X, Dubot-Pérès A. First isolation and genomic characterization of enterovirus $A 71$ and coxsackievirus A16 from hand foot and mouth disease patients in the Lao PDR. New Microbes New Infect. 2014;2(6):170-2.

120. Zhang Y, Nan LJ, Wu GS, Tan XJ, Xu DD, Gu SY, et al. The epidemiologic and virological analysis of an outbreak of hand, foot, and mouth disease in Inner Mongolia in 2007. Bing Du Xue Bao. 2009;25(3):159-65.

121. Tian XL, Zhang Y, Yan SH, Ma XE, Wang WR. The pathogenic spectrum of hand, foot and mouth disease and molecular characterizations of human enterovirus 71 in Inner Mongolia autonomous region in 2010. Bing Du Xue Bao. 2013;29(3):304-9.

122. Wittke V, Robb TE, Thu HM, Nisalak A, Nimmannitya S, Kalayanrooj S, et al. Extinction and rapid emergence of strains of dengue 3 virus during an interepidemic period. Virology. 2002;301(1):148-56.

123. Mauleekoonphairoj J, Vongpunsawad S, Puenpa J, Korkong S, Poovorawan Y. Complete genome sequence analysis of enterovirus 71 isolated from children with hand, foot, and mouth disease in Thailand, 2012-2014. Virus Genes. 2015:51(2):290-3.

124. Noisumdaeng P, Sangsiriwut K, Prasertsopon J, Klinmalai C, Payungporn S, Mungaomklang $\mathrm{A}$, et al. Complete genome analysis demonstrates multiple introductions of enterovirus 71 and coxsackievirus A16 recombinant strains into Thailand during the past decade. Emerg Microbes Infect. 2018;7(1):214.

\section{Publisher's Note}

Springer Nature remains neutral with regard to jurisdictional claims in published maps and institutional affiliations. 